\title{
Screening for mild cognitive impairment: If not now, when?
}

\author{
Sara B. Mitchell MD, Sandra E. Black MD
}

See also www.cmaj.ca/lookup/doi/10.1503/cmaj.141165, and CMAJ Open article www.cmajopen.ca/content/3/4/E419

$\mathrm{H}$ ealth care professionals, patients and families often identify Alzheimer disease by short-term memory impairment, which is its most recognizable clinical feature. Research involving genetically at-risk individuals has shown that the pathobiological process of Alzheimer disease begins in the brain decades before the onset of overt clinical symptoms. ${ }^{1}$ In this light, it seems only logical to suggest that strategies to combat dementia should be focused on preclinical detection to prevent progression of neurodegeneration. However, the Canadian Task Force on Preventive Health Care, in developing its new guideline on screening for cognitive impairment, found that we are still lacking the reliable tools both to identify and then to intervene at the preclinical stage of dementia. ${ }^{2}$ Hence, population-based screening for cognitive impairment in people 65 years of age and older is currently not justifiable. The guideline serves as an important indicator that advancements in the area of Alzheimer disease research are lagging, even in the face of the rapidly increasing prevalence of dementia that is leading to an escalating public health crisis in Canada and worldwide.

The number of Canadians living with dementia is expected to more than double from 2008 to 2038 , with a total economic burden of more than $\$ 872$ billion to Canadian society. ${ }^{3}$ Unlike the other leading causes of death in Canada, such as cancer and heart disease, there are currently no population-level screening or prevention strategies for Alzheimer disease, despite many international calls to action. Here, we set out what might be required to justify screening for cognitive impairment in asymptomatic individuals.

First, for screening efforts to be justified, a suitable population must be identified. Even though screening older adults for cognitive impairment may not yet be appropriate, one asymptomatic group that may benefit is firstdegree relatives of patients with dementia. This group is well known to be at increased risk of cognitive decline, especially if there is an identified autosomal dominant genetic mutation that confers a $50 \%$ chance of inheriting a mutation causing presenile onset. ${ }^{4}$ Even in sporadic Alzheimer disease, having one first-degree relative with dementia increases the lifetime risk for the disease as much as 2.5 -fold..$^{5}$ Moreover, relatives of patients with dementia may be more inclined than the general population to undergo screening, with as many as $50 \%$ showing willingness. ${ }^{2}$ If screening strategies prove fruitful in a smaller subset of the population, it might serve as an important stepping stone for larger-scale screening programs.

Second, once an appropriate screening sample is identified, the next step is to hone in on more sensitive screening tools for an asymptomatic cohort. Many concerned Canadians have already taken cognitive screening into their own hands, using new self-administered cognitive batteries such as the Cogniciti Brain Health Assessment (www.cogniciti.com) and Cogstate tests (http://cogstate.com) to screen themselves outside of the clinical setting. Concerns raised in the task force guideline ${ }^{2}$ over current office-based paper-and-pencil cognitive testing lie in the falsepositive rates for mild cognitive impairment with the Mini-Mental Status Examination (MMSE) and the Montreal Cognitive Assessment (MoCA). Moreover, the MMSE and MoCA are tools used to assess symptoms, not biomarkers of disease activity in the asymptomatic phase.

Identifying abnormal protein accumulation in the brain used to be confined to autopsy; however, research efforts to identify abnormal pro-
Competing interests: Sandra Black has received consulting fees from Boehringer Ingelheim, Novartis, GE Healthcare and Eli Lilly; speaker fees from Eisai and Novartis; and research support paid to her institution from Roche, GE Healthcare, Eli Lilly, Pfizer, Transition

Therapeutics and Cognoptix. No other competing interests were declared.

This article was solicited and has not been peer reviewed.

Correspondence to: Sandra Black, sandra. black@sunnybrook.ca

CMAJ 2016. DOI:10.1503 /cmaj.151411

All editorial matter in CMAJ represents the opinions of the authors and not necessarily those of the Canadian Medical Association. 
teins in vivo have been increasingly successful. A handful of biomarkers have been validated for use in current diagnostic criteria and in clinical trial settings: amyloid- $\beta 42$ protein in cerebrospinal fluid (CSF), CSF total tau and phosphorylated tau protein, amyloid imaging with positron emission tomography (PET), atrophy on structural magnetic resonance imaging, hypometabolism on fluorodeoxyglucose-PET and hypoperfusion on single-photon emission computed tomography. ${ }^{6}$ Several more exciting biomarkers are on the horizon, including tauspecific PET radioligands, ${ }^{7}$ serum markers such as plasma phospholipids ${ }^{8}$ and retinal amyloid imaging techniques. ${ }^{9} \mathrm{~A}$ crucial challenge in identifying a robust, affordable biomarker for Alzheimer disease is distinguishing the presence and activity of biomarkers in the normal aging brain compared with the diseased brain. Largescale natural history studies that observe these biomarkers in healthy individuals and those with the disease are under way. ${ }^{10}$

The final step is to find more effective preventive strategies and interventions for the preclinical phase. The real thrust behind the guideline recommendation against population screening is the seeming futility of screening. Even if a population is identified and a strong biomarker emerges, there is a paucity of effective preventive strategies and disease-modifying interventions for the preclinical phase. The mainstays of pharmacologic treatment of dementia with cholinesterase inhibitors and memantine have insufficient evidence for use in the preclinical or mild stages. ${ }^{2}$ Modification of diet and exercise, along with vigorous management of other vascular risk factors, may be preventive in the early stages of both Alzheimer disease and vascular dementia, as may be treatment of comorbid sleep and mood disorders. ${ }^{2}$ A plethora of potentially disease-modifying interventions have yielded disappointing results in clinical trials in the dementia stage, but researchers are moving quickly to study their effects in the asymptomatic stage in at-risk people (e.g., the A4 Study, http://a4study.org).

Collaborative provincial and national efforts to support neurodegenerative research are under way, including the Canadian Longitudinal Study on Aging (www.clsa-elcv.ca), the Canadian
Consortium for Neurodegeneration in Aging (www.cihr-irsc.gc.ca/e/46475.html), the Ontario Neurodegenerative Disease Research Initiative (ondri.ca) and the Consortium pour l'Identification précoce de la Maladie d'Alzheimer Québec (www.cima-q.ca), among others. Family physicians, geriatricians and other specialists play a key role in Canada's collective efforts to battle dementia by helping to identify appropriate asymptomatic or early symptomatic individuals willing to participate in critical research trials investigating biomarkers for Alzheimer disease and early interventions. If these trials yield promising results, preclinical screening for cognitive impairment will take on a new lens and purpose. For now, the recent Canadian Task Force on Preventive Health Care guideline serves as an unsettling reminder that we are far from having an effective response to an impending epidemic.

\section{References}

1. Bouras C, Giannakapoulos P, Michel JP, et al. Regional distribution of neurofibrillary tangles and senile plaques in the cerebral cortex of elderly patients: a quantitative evaluation of a one-year autopsy population from a geriatric hospital. Cereb Cortex 1994;4:138-50.

2. Canadian Task Force on Preventive Health Care. Recommendations on screening for cognitive impairment in older adults. CMAJ 2015 Nov. 30 [Epub ahead of print].

3. Rising tide: the impact of dementia on Canadian society - executive summary. Toronto: Alzheimer Society Canada; 2010. Available: www.alzheimer.ca/ /media/Files/national/Advocacy/ASC_ Rising_Tide_Exec_summary_e.pdf (accessed 2015 Nov. 18).

4. Sperling RA, Jack CR Jr, Aisen PS. Testing the right target and right drug at the right stage. Sci Transl Med 2011;3:111 cm33.

5. Green RC, Cupples LA, Go R, et al. Risk of dementia among white and African American relatives of patients with Alzheimer disease. JAMA 2002;287:329-36.

6. Jack CR Jr, Holtzman DM. Biomarker modeling of Alzheimer's disease. Neuron 2013;80:1347-58.

7. Johnson KA, Schultz A, Betensky RA, et al. Tau PET imaging in aging and early Alzheimer's disease. Ann Neurol 2015 Oct. 27 [Epub ahead of print].

8. Mapstone M, Cheema AK, Fiandaca MS, et al. Plasma phospholipids identify antecedent memory impairment in older adults. Nat Med 2014;20:415-8.

9. Frost S, Kanagasingam Y, Sohrabi H, et al. Retinal vascular biomarkers for early detection and monitoring of Alzheimer's disease. Transl Psychiatry 2013;3:e233.

10. Weiner MW, Veitch DP, Aisen PS, et al. Impact of the Alzheimer's Disease Neuroimaging Initiative, 2004 to 2014. Alzheimers Dement 2015;11:865-84.

Affiliations: Division of Neurology (Mitchell, Black), Department of Medicine, Sunnybrook Health Sciences Centre and University of Toronto; Hurvitz Brain Sciences Research Program (Black), Sunnybrook Research Institute, Toronto, Ont.

Contributors: Both authors contributed equally to the writing and revising of the manuscript, approved the final version to be published and agreed to act as guarantors of the work. 